\title{
Spatial analysis of the competitiveness of the high-speed train and air transport: The role of access to terminals in the Madrid-Barcelona corridor
}

\author{
Juan Carlos Martín, Concepción Román, Juan Carlos García-Palomares, Javier Gutiérrez
}

\begin{abstract}
This paper analyzes the effect of access and egress time to transport terminals over the spatial competiveness of the high-speed train (HST) in the Madrid-Barcelona (Spain) corridor, one of the densest airline domestic markets in the world. Applying spatial data from 2010 provided by a geographical information system (GIS) to a mode choice model estimated with sample travelers in this corridor, the present study examines whether and how the level-of-service of transport terminals spatially affects the competitiveness or modal distribution of HST and air transport in the provinces of Madrid and Barcelona; and, in particular, the degree of competitiveness that can be accrued by the access time provided by private car and transit in different market segments, especially mandatory and leisure trips. In a number of urban zones near train stations and airports, terminal accessibility clearly favors one transport mode in comparison to the other. Improving terminal accessibility via private car or public transit not only affects the relative access to terminals, but also represents a key strategy for readjusting the market shares of the competing modes in the corridor.
\end{abstract}

\section{Introduction}

High-speed trains (HST) are usually considered a sign of modernity and prosperity for those travellers who can be benefited from their use. In the European Union, France was the first nation inaugurating the line Paris-Lyon in 1981 after the relative success of the first line in the world, Tokyo-Osaka. China has now the world's most extensive network in absolute terms, followed by Spain ${ }^{1}$, Japan and France. According to Tapiador et al. (2009), the main nodal points in the intermodal networks of present-day Europe are the European high-speed train stations. 
HST competitiveness is highly influenced by the location (central or peripheral) of the stations and their accessibility by public and private transport (Huang and Morgan, 2011). Good access to transport terminals is a key element in the competitiveness of the transport modes for interurban passengers ${ }^{2}$. This is especially important when modeling the modal choice between HST and air transport, as these transport modes are close substitutes. Promoters of the HST have traditionally claimed an advantage over air transport in terms of the better accessibility to train stations in comparison with airports, normally located several kilometres away from the city center. Air transport, in contrast, remains still the most attractive alternative in terms of in-vehicle travel time. Considering that travellers choose the transport alternative with the maximum utility (or the minimum generalized cost), as stated in the classic theory of rational choice (McFadden, 1981), the effect of access and egress times over the attractiveness of the different transport alternatives should not be regarded as negligible. In particular, different patterns of access/egress times to/from transport terminals along the territory affect the modal competitiveness at the spatial level.

Accessibility to transport terminals stations has been analyzed in a number of studies under very different perspectives like for example in the analysis of: (1) multi airport systems (Pels et al., 2000, 2001, 2003); (2) service quality in HST stations and HST operators (Chang and Lee, 2008; Chou et al., 2011); (3) catchment areas of railways stations according to different access transport modes (Rietveld, 2000; Martens, 2004; Givoni and Rietveld, 2007); (4) modal competition in interurban transport (Wardman and Tyler, 2000; Clever and Hansen, 2008; Román et al., 2010; Román and Martín, 2011); (5) comparison of the catchment areas between HST stations and airports (Dobruszkes, 2011) .

For example, Chang and Lee (2008) find that poor HST station accessibility is after the price the main reason for not using the Korean HST. Likewise in Taiwan, Chou et al. (2011) find that HST station, mostly away from the city center, make that the access to the terminals is perceived as the least appreciated attribute of the service quality by HST users. Clever and Hansen (2008) highlight in this respect that for a given line-haul travel time, the modal competition depends more on the access and egress times to the transport terminals. Summarizing, it can be said that: (1) access time to terminals plays a significant role in determining their catchment area for the different access transport modes; (2) the relative competiveness of each mode seems to be highly affected by the spatial location of the terminals being all other factors similar, that is HST is more competitive when train stations access presents an advantage over airports; (3) access to terminals are usually in the top-priority quality indicators that need to be addressed in order to improve customer satisfaction; (4) it is the door-to-door travel time and its quality and not that of station-to-station or airport-to-airport travel time that are important in mode choice decision (Givoni and Dobruszkes, 2013).

There are also a number of papers analyzing interurban modal competition between HSTs and other transport modes. Most of them used discrete choice analyzes, based on SP (Stated Preference), RP (Revealed Preference) or mixed data (see e.g., Bel, 1997; Chang and Chang, 2004; González-Savignat, 2004; Ivaldi and Vibes, 2005; Román et al., 2007; Mao, 2010; Román and Martín, 2011; Pagliara et al., 2012). The corridors under analysis, the variables included and the type of data vary on diverse circumstances, but it can be said that in general, total travel time -which includes access/egress, schedule delay and in-vehicle travel time-, fare, comfort, reliability are the most common variables that characterize the service levels of the transport modes. Other variables that affect passengers' mode choice are more related with socio-economic characteristics of the travellers or the trip, e.g. gender, income and leisure or mandatory trip. However, this literature does not provide any analysis of the spatial effects in the territory around the transport terminals.

Spatial effects of HSTs have been previously studied at a macro level, using regions or provinces as the unit of analysis (see e.g. Fröidh, 2005; Gutiérrez et al., 1996; Gutiérrez, 2001; Martín et al., 2004; Vickerman et al., 1999). These papers analyze the effects of the spatial accessibility component for a particular transport investment without considering how the equilibrium between different transport modes will evolve, that is there is not any consideration of modal competition. In this study, we extend the previous literature analyzing not only the presence of a HST station or an airport as a driver of transport mode attractiveness, but also the 'level-of-service' provided. The term 'level-of-service' comprises many aspects that affect modal competitiveness and one of them - access times to transport terminals -is the focus of this paper.

This research attempts to integrate these two scientific traditions that have evolved separately: accessibility analysis to transport terminals and modal choice modeling. The paper extends the previous literature on accessibility to transport terminals and their spatial effects at a more micro-level unit, analyzing the effect that access and egress times to transport terminals has over the spatial distribution of the modal shares of the HST and air transport within the metropolitan areas of Madrid and Barcelona. The corridor under analysis links the two most important economic poles in Spain, and the HST is directly competing with one of the densest domestic airline markets in the world. It is clear that when HST entered in operation, its attractiveness, versus other transport modes, such as coach, private cars, or air transport, increased. However, as we will see, this attractiveness is very different at spatial level around the transport terminals.

Therefore, we will address this up-to-now neglected aspect of interurban transport competitiveness, whether and how the level-of-service of transport terminals affects the relative attractiveness of HST and air transport. The analysis will be made using two different access modes, private car and transit, and two different market segments, mandatory and leisure

\footnotetext{
2 Other important components have been analyzed in Schönharting et al. (2003), where six criteria (short time intervals, sufficient parking, integrated timetables, integrated tariffs, connected crossings and short-distance transfers) were studied in order to characterize the relative importance for the different intermodal combinations that can occur at an HST station (HST-private car, HST-taxi, HST-transit). Pagliara et al. (2012) analyzed the modal competition in the corridor Madrid-Barcelona, finding that check-in and security controls at the airport are a crucial variable for users in making their modal choices, but other policies, such as the improvement of parking facilities at train stations, play a secondary role.
} 
trips. For this purpose, the results of a discrete choice model that includes respondent heterogeneity and interaction effects are applied to a geographic information system (GIS) that takes into account different zones of the metropolitan areas of Madrid and Barcelona. The access time from/to zones located in the vicinity of Atocha (the Madrid HST station), Barajas (the Madrid airport), Sants (the Barcelona HST station) and El Prat (the Barcelona airport) are analyzed using a GIS. To our knowledge, this is the first time these two tools are used together in a sequential order (discrete choice and GIS) for analyzing how the access times to terminals affect the modal attractiveness of two competing transport modes. As a result, it will be possible to analyze the spatial effects of the access times to the terminals on the relative attractiveness of the HST and air transport.

In summary, for the first time a detailed spatial analysis of the influence of access times to terminals is obtained using previous information of an intermodal competition model. This is not as simple as considering just the journey time from the city center of Madrid or Barcelona to the transport terminals. Many passengers travel from either the suburbs or the area around the city. It is overly simplistic and inappropriate to infer a better accessibility to rail stations for just a simple node of the city - the city center -, as most of the passengers do not depart or travel to this exact point.

The rest of this paper is organised as follows. The next section, Section 2, describes the data set, the questionnaire and the experimental design. Section 3 describes the choice model estimated to analyze the modal competition in the Madrid-Barcelona corridor. The results of the GIS analysis are then presented in Section 4, focusing on the spatial analysis of the relative competitiveness of air versus HST transport. In that section we also discuss how the relative access times to terminals influence the modal competitiveness for different types of trips and access modes. Finally, Section 5 provides a conclusion.

\section{Collecting the data set}

The analysis is based on mixed revealed preference (RP) / stated preference (SP) data set containing information about travel behavior in the Madrid-Barcelona corridor before the entrance of the new HST alternative. RP data were obtained from users of the main transport modes in the corridor: conventional train, air transport, coach, riding in car as driver and riding in car as passenger. Sampled travellers completed a questionnaire specifically designed for this purpose and containing four different sections: identification data, trip information and both household and personal socioeconomic data. Trip information included questions related not only to the actual mode, but also to those available alternatives that were not chosen by the individual for the reference trip.

SP data were based on a stated choice (SC) experiment designed for air transport passengers in order to analyze modal competition between HST and air transport. The purpose of the experiment was to gain insight into passengers' preferences with regard to transport mode choice and to study whether access and egress times to terminals are an important attribute determining the relative competitiveness of HST versus air transport. Bliemer and Rose (2011) sustain that discrete choice experiments (DCE) represent a popular and adequate technique that allows researchers to construct databases for modeling transport behavior preferences. In a DCE, a respondent is asked in one or multiple choice tasks to select his or her highest preference from a given set of alternatives that are characterized by different levels of attributes.

In our case, the DCE dealt specifically with air travel choice entering into competition with the new HST service and included the typical level-of-service attributes such as travel time, access/egress time, travel cost and frequency. We also included two latent variables: reliability and comfort. The former was included to account for the negative effect of delays over the scheduled departure time, and the latter to determine the effect of having more space in plane seats. Respondents were asked to complete computer-aided DCE tasks involving the choice between the plane they were ready to board and the new HST. Each individual faced nine choice tasks in which the attributes shown were varied according to the selected experimental design. To make the tasks more realistic, the levels assigned to some attributes in the SC exercise were customized to each respondent's experience; incorporating and pivoting information provided by some previous questions included in the questionnaire about the reference alternative (the plane, in this case). Therefore, the levels of travel cost and access/egress time were defined in terms of the values experienced by the sample respondents; plausible percentage variations according to available information about future fares and access/egress times for the HST were also considered. The service frequency was also customized in respect to the departure time declared by the respondent. Attributes and levels considered in the experiment are presented in Table $1 .{ }^{3}$

The mixed or joint estimation method proposed by Bradley and Daly (1997), combining RP and SP data, allowed us to estimate the utility of the new HST alternative and of those modes that already existed. The main interest of our model lies in analyzing the principal factors that influence the modal choice in the corridor after the introduction of the HST. In the analysis, special attention was given to the perception of access and egress time to the train stations and airports. Thus, total travel time was divided into its principal components: access, egress and in-vehicle travel time.

Table 2 presents a summary of the descriptive analysis of the sample. The data set is part of a research project financed by the Spanish Ministry of Transport with the main purpose of analyzing potential demand for new HST services in the MadridBarcelona corridor (see Román et al., 2010 for more details about the project). We want to highlight here that what has been done in Román et al. (2010) and in Román and Martín (2011) is the analysis of the modal competition. However, the model in the present paper was a little bit changed as we separate the effect of access and egress times because we now analyze the

\footnotetext{
${ }^{3}$ Interested readers can obtain further details about the DCE and revealed preference (RP) data in Román and Martín (2011).
} 
Table 1

Attributes and levels.

\begin{tabular}{|c|c|c|c|c|c|}
\hline \multirow[t]{2}{*}{ Attributes } & \multirow[t]{2}{*}{ Levels } & \multicolumn{4}{|l|}{ Mode } \\
\hline & & Plane & & HST & \\
\hline \multirow[t]{3}{*}{ Travel cost $\left(c_{v}\right)$} & -1 & $c_{v}^{*} 1.10$ & & $c_{v}$ & \\
\hline & 0 & $c_{v}$ & & $c_{v}^{*} 0.90$ & \\
\hline & +1 & $c_{v}^{*} 0.90$ & & $c_{v}{ }^{*} 0.80$ & \\
\hline \multirow[t]{3}{*}{ Travel time $\left(t_{v}\right)$} & -1 & $1 \mathrm{~h} 20 \mathrm{~min}$ & & $2 \mathrm{~h} 45 \mathrm{~min}$ & \\
\hline & 0 & $1 \mathrm{~h} 10 \mathrm{~min}$ & & $2 \mathrm{~h} 30 \mathrm{~min}$ & \\
\hline & +1 & $1 \mathrm{~h}$ & & $2 \mathrm{~h} 15 \mathrm{~min}$ & \\
\hline \multirow{3}{*}{$\begin{array}{l}\text { Access + Egress time } \\
\quad\left(t_{a}\right)\end{array}$} & -1 & $t_{a}^{*} 1.20$ & & $t_{a}$ & \\
\hline & 0 & $t_{a}$ & & $t_{a}^{*} 0.90$ & \\
\hline & +1 & $t_{a}^{*} 0.80$ & & $t_{a}^{*} 0.80$ & \\
\hline \multirow[t]{3}{*}{$\begin{array}{l}\text { Frequency (Headway) } \\
\quad(f)\end{array}$} & & Departure before 9:00 am & $\begin{array}{l}\text { Departure after } \\
9: 00 \mathrm{am}\end{array}$ & Departure before 9:00 am & $\begin{array}{l}\text { Departure after } \\
9: 00 \mathrm{am}\end{array}$ \\
\hline & -1 & Every $30 \mathrm{~min}$ & Every $60 \mathrm{~min}$ & Every $60 \mathrm{~min}$ & Every $90 \mathrm{~min}$ \\
\hline & +1 & Every $15 \mathrm{~min}$ & Every $30 \mathrm{~min}$ & Every $30 \mathrm{~min}$ & Every $60 \mathrm{~min}$ \\
\hline \multirow[t]{3}{*}{ Reliability $(r)$} & -1 & 30-min delay (Inside the plane) & & 10-min delay & \\
\hline & 0 & 15 -min delay (in the boarding gate) & & 5 -min delay & \\
\hline & +1 & Departure on time & & Departure on time & \\
\hline \multirow[t]{2}{*}{ Comfort (C) } & -1 & $\begin{array}{l}\text { Low: Insufficient leg room Narrow } \\
\text { seats }\end{array}$ & & $\begin{array}{l}\text { High: Ample leg room Wide } \\
\text { seats }\end{array}$ & \\
\hline & +1 & High: Ample leg room Wide seats & & & \\
\hline
\end{tabular}

Notes: $c_{v}=$ Travel cost in plane.

$t_{a}=$ Access + Egress time in plane.

Table 2

Main characteristics of the sample, Madrid-Barcelona corridor (2004).

\begin{tabular}{|c|c|c|c|c|c|c|}
\hline & \multicolumn{6}{|c|}{ Chosen mode } \\
\hline & Car driver & Car passenger & Bus & Train & Plane & Total \\
\hline Choice & 38 & 18 & 39 & 51 & 295 & 441 \\
\hline Availability $^{\mathrm{a}}$ & 165 & 92 & 165 & 288 & 435 & - \\
\hline \multicolumn{7}{|c|}{ LEVEL-OF-SERVICE ATTRIBUTES (Average per available alternative) } \\
\hline Access time (minutes) & - & - & 27 & 29 & 36 & - \\
\hline Waiting time (minutes) & - & - & 40 & 28 & 58 & - \\
\hline In-vehicle time (minutes) & 357 & 369 & 477 & 332 & 59 & - \\
\hline Egress time (minutes) & - & - & 33 & 39 & 37 & - \\
\hline Travel cost or fuel $(€)$ & 46.07 & 22.70 & 25.13 & 62.33 & 95.19 & - \\
\hline Toll $(€)$ & 18.32 & 4.45 & - & - & - & - \\
\hline Access cost $(€)$ & - & - & 2.66 & 5.47 & 7.31 & - \\
\hline Egress cost $(€)$ & - & - & 3.50 & 7.07 & 7.91 & - \\
\hline Headway (minutes) & - & - & 46 & 150 & 33 & - \\
\hline \multicolumn{7}{|c|}{ SOCIOECONOMIC CHARACTERISTICS (Classification per chosen mode) } \\
\hline Trip motive: work or education & $16(42 \%)$ & $3(17 \%)$ & $10(26 \%)$ & $31(61 \%)$ & $187(63 \%)$ & $247(56 \%)$ \\
\hline Trip motive: other & $22(58 \%)$ & $15(83 \%)$ & $29(74 \%)$ & $20(39 \%)$ & $108(37 \%)$ & $194(44 \%)$ \\
\hline Men & $26(68 \%)$ & $8(44 \%)$ & $15(38 \%)$ & $28(55 \%)$ & $160(54 \%)$ & $237(54 \%)$ \\
\hline Women & $12(32 \%)$ & $10(56 \%)$ & $24(62 \%)$ & $23(45 \%)$ & $135(46 \%)$ & $204(46 \%)$ \\
\hline Age (average) & 41 & 31 & 28 & 39 & 36 & 36 \\
\hline Per capita weekly income (average $€$ ) & 355.93 & 166.89 & 188.25 & 341.57 & 350.68 & 328.88 \\
\hline Expenditure rate $^{\mathrm{b}}$ (average) & 2.86 & 1.23 & 1.41 & 2.68 & 2.81 & 2.62 \\
\hline
\end{tabular}

${ }^{a}$ It can be seen that not all types of public transport are available to passengers. When passengers consider that under no circumstance would they travel by some specific mode, then this transport mode is not available in the choice set.

b Per capita family income/available time.

spatial competitiveness effects only for the public transport modes which are considered more close substitutes in Madrid and Barcelona using a GIS method.

In the corridor under study, total travel time by plane is substantially less than in the rest of the modes but, in this case, the proportion of access and waiting time (over the total duration of the journey) is very high (nearly $70 \%$ ). The car is the second-fastest mode, with a total travel time of 70 min less than by train. ${ }^{4}$ Nearly $56 \%$ of the trips were mandatory (work and education), and $54 \%$ of the travellers men. We also observed differences in per capita weekly income, ranging from $€ 167$

\footnotetext{
${ }^{4}$ It is important to point out that the new HST will reduce the in-vehicle travel time for the train by approximately $50 \%$.
} 
Table 3

Market shares of the population and the sample.

\begin{tabular}{lcr}
\hline Mode & Population $^{*}$ & Sample \\
\hline Car & $21 \%$ & $12.7 \%$ \\
Bus & $8 \%$ & $8.8 \%$ \\
Train & $12 \%$ & $11.5 \%$ \\
Plane & $59 \%$ & $66.8 \%$ \\
\hline
\end{tabular}

${ }^{*}$ Estimated figures obtained from Gonzalez-Savignat (2000).

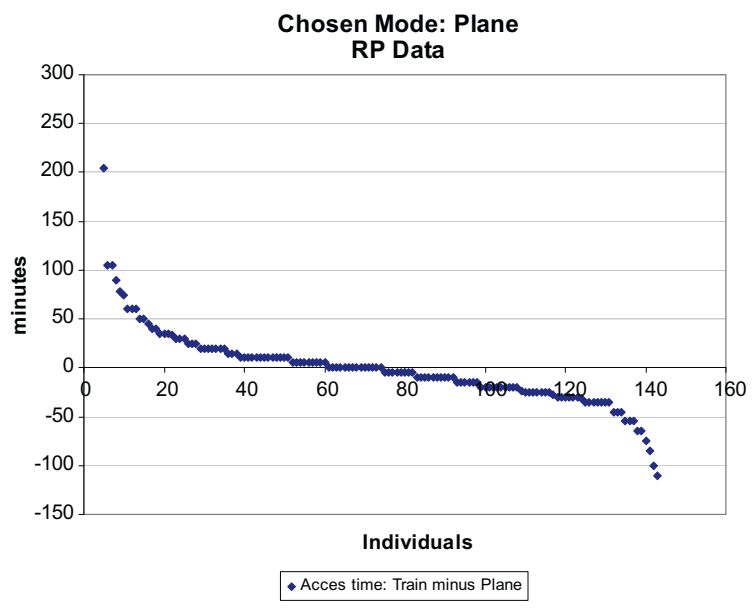

Fig. 1. Differences in access time to terminals for plane travellers.

for car passengers to $€ 351$ and $€ 355$ for plane passengers and car drivers, respectively. And finally, the expenditure rate ${ }^{5}$ goes from 1.23 for car passengers to 2.86 for car drivers.

Modal shares in the sample were determined by trying to replicate modal shares in the population, given the available information at the time the surveys were carried out and considering a maximum error of $10 \%$ according to the following expression (Ortúzar and Willumsen, 2001):

$$
n>\frac{p(1-p)}{\left(\frac{e}{Z_{\alpha}}\right)^{2}+\frac{p(1-p)}{N}},
$$

where $n$ is the sample size for the mode with the lowest share, $\mathrm{p}$ is the modal share in the population, $e$ is an acceptable error and $Z_{\alpha}$ is the standard Normal value for the required confidence level.

Table 3 shows the modal distribution in the sample and the population ${ }^{6}$.

The distribution of surveys throughout the day and during different days of the week took into account the peak and offpeak periods in the corridor according to the current supply. Passengers participating in the survey were selected at random near the boarding gates of the corresponding flights and in the departure areas of the train and bus stations.

Figs. 1 and 2 show the differences in access time to terminals for plane and train passengers, respectively. It can be seen that the access time to airports was less than the access time to train stations for only $54 \%$ of the travellers who chose to take the plane (Fig. 1), which means that $46 \%$ of the individuals who travelled by plane considered this alternative more competitive in other level-of-service attributes. It can be inferred that, for these passengers, it is possible that in-vehicle travel time and frequency are more valued attributes. However, for the majority of the train travellers (91\%), access time to train stations was significantly lower than it was to airports. So, at first glance, this attribute may be quite sensitive in determining the overall attractiveness of the new HST (Fig. 2).

\footnotetext{
${ }^{5}$ This variable was used in the specification of the model, as we will see below.

${ }^{6}$ Unfortunately, more updated information about the modal distribution in the corridor was not available at the time of the survey, provided the difficulty of obtaining information of private car users. Notwithstanding, experts in the in the Spanish Ministry of Transport suggested us to correct sample figures by increasing the modal share of the plane, as in their opinion, the figures for the car were too high and they also considered that the HST was a closer substitute to air transport in the corridor Madrid Barcelona .
} 


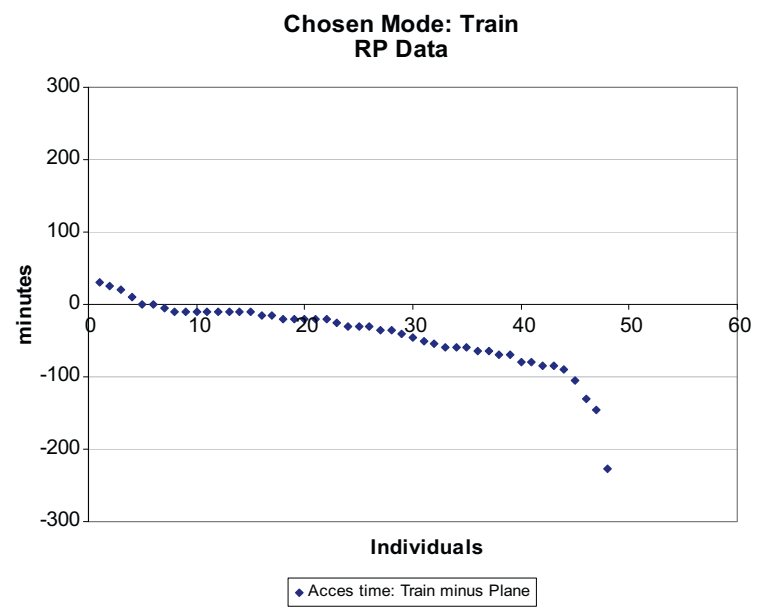

Fig. 2. Differences in access time to terminals for train travellers.

\section{The discrete choice model}

Discrete choice models are derived under the assumption of utility-maximizing behavior by the decision maker. The specification of the econometric model is based on random utility theory (Domencich and McFadden, 1975; Ortúzar and Willumsen, 2001). It states that the utility of alternative $j$ for individual $q$ has the expression:

$$
U_{j q}=V_{j q}+\varepsilon_{j q},
$$

where $V_{j q}$ is the representative or systematic utility; ${ }^{7}$ and $\varepsilon_{j q}$ is a random term that includes unobserved effects. $V_{j q}$ depends on the observable attributes of alternative $j$, and on the socioeconomic characteristics of individual $q$. When $\varepsilon_{j q}$ are distributed iid Gumbel, we obtain the popular multinomial logit (MNL) model. The nested logit (NL) model (Williams, 1977) is appropriate when the set of options available for a decision maker can be grouped into nests in such a way that the independence-of-irrelevant-alternatives property of the MNL holds for alternatives within the same nest, and does not hold for options belonging to different nests. This model is obtained when the vector of random terms follows the generalized extreme value distribution.

The mixed estimation combining RP and SP data is based on the hypothesis that variances of the error terms in both data sets are proportional (Ben-Akiva and Morikawa, 1990), and can be expressed as:

$$
\sigma_{\varepsilon}^{2}=\mu^{2} \sigma_{\eta}^{2}
$$

where $\mu$ is an unknown scale parameter, and $\varepsilon$ and $\eta$ are the error terms of the RP and SP utilities, respectively. This leads to the following utility functions for a given alternative $j$ :

$$
\begin{aligned}
& U_{j}^{R P}=V_{j}^{R P}+\varepsilon_{j}=\theta X_{j}^{R P}+\alpha Y_{j}^{R P}+\varepsilon_{j} \\
& \mu U_{j}^{S P}=\mu\left(V_{j}^{S P}+\eta_{j}\right)=\mu\left(\theta X_{j}^{S P}+\omega Z_{j}^{S P}+\eta_{j}\right),
\end{aligned}
$$

where $\theta, \alpha$ and $\omega$ are parameters to be estimated; $X_{j}^{R P}$ and $X_{j}^{S P}$ are attributes common to the RP and SP data sets; and $Y_{j}^{R P}$ and $Z_{j}^{S P}$ are attributes that only belong to the designated data set.

Bradley and Daly (1997) proposed an estimation method based on the construction of an artificial NL structure where RP alternatives are placed right below the root, and each SP alternative is placed in a single-alternative nest with a common scale parameter $\mu$. This procedure will ensure that $\mu$ is estimated to obtain uniform variance. ${ }^{8}$

Once $\mu$ is estimated, you can build a utility function using common and non-common RP-SP parameters (Louviere et al., 2000). If attributes are only defined for the SP case, their parameters must be scaled by $\mu$. However, those corresponding to attributes measured in the RP base do not need to be scaled, even if they only appear in the SP utility (Cherchi and Ortúzar, 2004).

\subsection{Model specification}

We considered a linear-in-the-parameter (but not linear-in-the-attributes) specification for the utility function that included transport costs divided by the expenditure rate (Jara-Díaz and Farah, 1987). As the data we obtained indicated a

\footnotetext{
${ }^{7}$ In fact, it is the conditional indirect utility obtained when we analyze the consumer problem in a context of discrete choice (McFadden, 1981; Jara-Díaz, 1998).

${ }^{8}$ This method is known in the literature as the Bradley and Daly nested logit trick.
} 
significant proportion of household income spent on transport, ranging from 5 to $27 \%$ for the different modes, we included cost squared terms as recommended by Jara-Díaz (1998). In order to account for a more rich specification of the access/ egress time to train stations and airports, we defined the interaction of this variable with the travel time. We also considered the interaction of the trip motive with travel time. This allowed us to analyze the perception of travel time in terms of the trip motive. The utilities for the RP and SP alternatives were:

$$
\begin{aligned}
& \text { RP ALTERNATIVES : } \\
& U_{c a r-d r i v e r}^{R P}=C_{c d}+\left(\theta_{t_{v}}+\theta_{t_{v}^{*}} T\right) t_{v}+\theta_{c / e_{r}} \frac{c}{e_{r}}+\theta_{c^{2} / e_{r} I} \frac{c^{2}}{e_{r} I} \\
& U_{c a r-p a s s e n g e r}^{R P}=C_{c p}+\left(\theta_{t_{v}}+\theta_{t_{v}^{*} T} T\right) t_{v}+\theta_{c / e_{r}} \frac{c}{e_{r}}+\theta_{c^{2} / e_{r} I} \frac{c^{2}}{e_{r} I} \\
& U_{b u s}^{R P}=C_{b}+\theta_{t_{a}} t_{a}+\theta_{t_{e}} t_{e}+\left(\theta_{t_{v}}+\theta_{t_{v}^{*} T} T\right) t_{v}+\theta_{c / e_{r}} \frac{c}{e_{r}}+\theta_{c_{v}^{2} / e_{r} I} \frac{c^{2}}{e_{r} I} \\
& U_{\text {train }}^{R P}=C_{\text {train }}+\theta_{t_{a}} t_{a}+\theta_{t_{e}} t_{e}+\left(\theta_{t_{v}}+\theta_{t_{v}^{*} T} T\right) t_{v}+\theta_{c / e_{r}} \frac{c}{e_{r}}+\theta_{c^{2} / e_{r} I} \frac{c^{2}}{e_{r} I}+\theta_{f} f \\
& U_{\text {plane }}^{R P}=\theta_{t_{a}} t_{a}+\theta_{t_{e}} t_{e}+\left(\theta_{t_{v}}+\theta_{t_{v}^{*} T} T\right) t_{v}+\theta_{c / e_{r}} \frac{c}{e_{r}}+\theta_{c^{2} / e_{r} I} \frac{c^{2}}{e_{r} I}+\theta_{f} f
\end{aligned}
$$

\section{SP ALTERNATIVES :}

$$
\begin{aligned}
U_{H S T}^{S P} & =\theta_{t_{a}} t_{a}+\theta_{t_{e}} t_{e}+\left(\theta_{t_{v}}+\theta_{t_{v}^{*} T} T\right) t_{v}+\theta_{c / e_{r}} \frac{c}{e_{r}}+\theta_{c^{2} / e_{r} I} \frac{c^{2}}{e_{r} I}+\theta_{f} f+\theta_{r} r \\
U_{\text {plane }}^{S P} & =\theta_{t_{a}} t_{a}+\theta_{t_{e}} t_{e}+\left(\theta_{t_{v}}+\theta_{t_{v}^{*} T} T\right) t_{v}+\theta_{c / e_{r}} \frac{c}{e_{r}}+\theta_{c^{2} / e_{r} I} \frac{c^{2}}{e_{r} I}+\theta_{f} f+\theta_{r} r+\theta_{\text {COM }^{*} t_{v}} C O M \cdot t_{v}
\end{aligned}
$$

where, $t_{v}$ is in-vehicle travel time; $t_{a}$ is access time, $t_{e}$ is egress time; $c$ is travel cost; $f$ is service headway; $r$ is reliability (minutes of delay); COM is equal to 1 if the level of comfort is high (more space and leg room in the plane seat); $T$ is equal to 1 if the trip motive is work or education; $e_{r}$ is the expenditure rate; $I$ is per capita family income; and the $\theta s$ are unknown parameters. Regarding the model structure, we estimated an NL model that considers the correlation between train and plane. This means that individuals perceive these alternatives as close substitutes.

\subsection{Estimation results}

Table 4 shows the estimation results corresponding to the best model obtained. All parameter estimates have the expected signs, and were significant at an acceptable confidence level, with only the exceptions of the interactions between travel time and mandatory trips and between travel time and comfort. The alternative specific constants (taking plane as the reference) turned out to be significant (except for the train), ${ }^{9}$ and with a negative sign, indicating that plane (or train) would be preferred if the effect of the other attributes were zero. The parameter of egress time is significant and higher than the parameter of access time, meaning that the disutility associated with egress time is higher than that associated with access time. The usual pattern associated with the parameters of access/egress time versus in-vehicle time is also seen in our model. ${ }^{10}$

Regarding model structure, we use different NL specifications to test the substitution patterns between the alternatives. In the final specification we found correlation between the HST and plane. This indicates that in the individuals' decisionmaking process, there exists a higher level of substitution between these two alternatives than between others.

During the modeling process we analyze RP and SP models separately and we test the proportionality hypothesis of the parameter vectors in both datasets as suggested by Louviere et al. (2000).

\subsection{Elasticities, choice probabilities and odds}

The elasticities are reported in Table 5, and they are obtained as the weighted aggregate average of individual elasticities. We first report the direct elasticities of the probability of air transport and HST with respect to the cost, access time, egress time, travel time and headway. It can be seen that the cost elasticities are higher (in absolute value) than the rest service elasticities. Regarding the time components, it is noted that both transport modes present different results, as in air transport the access and egress time elasticities seems to be relatively more important than in-vehicle travel time elasticity, while the opposite holds true for the HST. Nevertheless both modes present a similar pattern regarding the egress time elasticity that is more important than the access time elasticity. Analyzing the cross elasticities, Table 5 shows that both transport operators could compete via prices as the cross cost elasticities are higher than the cross travel time and headway elasticities ${ }^{11}$. Thus,

\footnotetext{
${ }^{9}$ It was not included in the final model.

${ }^{10}$ This result reflects evidence that passengers tend to prefer a short access time even at the cost of a longer in-vehicle time. SDG (2006) weighted access time by a factor of 2 when calculating its impact on market share.

${ }^{11}$ The elasticities reported in this paper are very similar to those obtained in Román et al. (2010), where the differences observed are basically explained by the disaggregation of the effects of access and egress times of the current paper. Román et al. (2010) also analyzed the demand response of the entrance of the new HST alternative to the application of different policy measures.
} 
Table 4

Estimation results.

\begin{tabular}{|c|c|c|}
\hline Parameter & & Estimates ( $t$-ratios) \\
\hline Car-driver constant & $C_{c d}$ & $\begin{array}{l}-3.375 \\
(-2.8)\end{array}$ \\
\hline Car-passenger constant & $C_{c p}$ & $\begin{array}{l}-4.39 \\
(-3.2)\end{array}$ \\
\hline Bus constant & $C_{b}$ & $\begin{array}{l}-2.942 \\
(-2.4)\end{array}$ \\
\hline Travel time $\left(t_{v}\right)$ & $\theta_{t v}$ & $\begin{array}{l}-0.007638 \\
(-3.9)\end{array}$ \\
\hline Travel cost $/ e_{r}\left(c / e_{r}\right)$ & $\theta_{c / e_{r}}$ & $\begin{array}{l}-0.06714 \\
(-5.5)\end{array}$ \\
\hline Access time $\left(t_{a}\right)$ & $\theta_{t a}$ & $\begin{array}{l}-0.02072 \\
(-2.6)\end{array}$ \\
\hline Travel $\operatorname{cost}^{2} / e_{r} I\left(c^{2} / e_{r} I\right)$ & $\theta_{c^{2} / e_{r}}$ & $\begin{array}{l}0.02135 \\
(4.0)\end{array}$ \\
\hline Egress time $\left(t_{e}\right)$ & $\theta_{t e}$ & $\begin{array}{l}-0.02609 \\
(-3.5)\end{array}$ \\
\hline Headway $(f)$ & $\theta_{f}$ & $\begin{array}{l}-0.001477 \\
(-0.4)\end{array}$ \\
\hline Reliability (delay) $(r)$ & $\theta_{r}$ & $\begin{array}{l}-0.03587 \\
(-3.6)\end{array}$ \\
\hline Travel time ${ }^{*}$ Comfort high $\left(\mathrm{COM}^{*} t_{v}\right)$ & $\theta_{\mathrm{COM} * \mathrm{tv}}$ & $\begin{array}{l}0.004405 \\
(1.6)\end{array}$ \\
\hline HST-Plane nest parameter & $\Phi$ & $\begin{array}{l}0.3470 \\
(3.3) \\
{[-6.21]^{a}}\end{array}$ \\
\hline Scale factor SP & $\mu$ & $\begin{array}{l}0.4486 \\
(3.73) \\
{[-4.59]^{a}}\end{array}$ \\
\hline $\mathrm{l}^{*}(0)$ & & -2124.80 \\
\hline $1^{*}(\vartheta)$ & & -2085.82 \\
\hline Observations & & 2917 \\
\hline
\end{tabular}

a $t$-ratio with respect to $\Phi=1$ and $\mu=1$.

Table 5

Elasticities of choice probabilities of air transport and HST with respect to some service attributes.

\begin{tabular}{llc}
\hline Attributes of the own mode & Air Transport & HST \\
\hline Direct elasticities & & \\
Cost & -0.83 & -0.60 \\
Access time & -0.27 & -0.18 \\
Egress time & -0.39 & -0.28 \\
Travel time & -0.21 & -0.47 \\
Headway & -0.02 & -0.04 \\
Attributes of the competing mode & Air Transport & HST \\
\hline Cross elasticities & & \\
Cost & 0.72 & 0.69 \\
Access time & 0.22 & 0.23 \\
Egress time & 0.33 & 0.32 \\
Travel time & 0.57 & 0.17 \\
Headway & 0.04 & 0.02 \\
\hline
\end{tabular}

our model suggests that access cost is a dominant explanatory factor of modal competition in this corridor. The low values of the headway elasticities are also related to the low significance level of the headway parameter and that to these two transport modes serviced the corridor with a very high frequency. Finally, note that passengers are more sensitive to egress time than to access time so then the location of the terminals play an important role in the potential competitiveness of these two transport modes.

To analyze competition between the HST and air transport, we compute the probability of choosing plane or train, conditional to the election of the nest according to the NL structure of the estimated model, being the choice probabilities represented by:

$$
P_{H S T}=P\left(\left.H S T\right|_{N E S T}\right)=\frac{e^{U_{H S T}}}{e^{U_{H S T}}+e^{U_{\text {Plane }}}} \quad P_{\text {Plane }}=P\left(\text { Plane }\left.\right|_{N E S T}\right)=\frac{e^{U_{\text {Plane }}}}{e^{U_{H S T}}+e^{U_{\text {Plane }}}}
$$


where $U_{\text {Plane }}$ and $U_{H S T}$ represent the estimated hybrid utility containing common and non-common RP-SP parameters (see Louviere et al., 2000 for more details) properly scaled as recommended by Cherchi and Ortúzar (2004).

We will reflect how the location of the terminals, that is the airport and the train station in Madrid and Barcelona, affects the modal competitiveness at the spatial level of the two provinces in the next section considering the spatial distribution of the odds of using air transport.

The odds of using air transport is defined as the ratio: $\frac{P_{\text {Plane }}}{P_{\text {HST }}}=e^{U_{\text {Plane }}-U_{\text {HST }}}$. This ratio represents the relative odds of using air transport, that is, when this ratio is higher than one then the odds are slightly stacked towards air transport meaning that air transport is more competitive as the probability of travelling by air transport is higher than the probability of selecting HST for a particular observation. This observation can be a traveller or as in our case a determined zone of the provinces for particular trips. When the ratio is one or in small neighbourhood of one, this can be interpreted as if air transport and HST are equally competitive, as the probabilities of choosing air transport or HST are very similar. On the contrary when the odds are lower than one, then HST is more competitive. In essence, the authors through the use of the discrete choice model build a tool that it similar to the coin toss, the paradigmatic model of all odds games. Evidence of the validity of this approach comes from research into different areas as the conduct and performance of financial markets and gambling-both instances involving groups of individuals all seeking to obtain some advantage through the use of information and knowledge. Gambling odds have also been shown to be efficient synthesizers of knowledge from groups of individuals ranging from sports events to election outcomes (Ioannidis and Peel 2005).

\section{Spatial analysis}

A Geographic Information System (ArcGIS) was used to store the population, employment and network data. Thus, access time to Madrid-Atocha HST Station and Madrid Barajas Airport, by private and public transport were stored in order to further analyze whether the relative position of the zones in Madrid favor the competitiveness of HST or air transport. In a similar way, egress time to terminals in Barcelona, Barcelona Sants HST Station and Barcelona El Prat Airport, by private and public transport, were also stored to further analyze whether the relative position of the zones in Barcelona favor the competitiveness of HST or air transport. Thus, an ample range of potential origin and destination zones can be spatially analyzed with our model.

The metropolitan area of Madrid was divided into 69 zones, corresponding to the 21 districts of the municipality of Madrid and the 48 suburban municipalities. The metropolitan area was grouped into four different rings and nine quadrants, in order to present a summary of the results of our analysis. The first ring includes the 7 central districts of the municipality of Madrid, the second covers the 14 peripheral districts of the municipality of Madrid, the third ring includes the 26 suburban municipalities which were already integrated in the metropolitan area in the 1960s and 1970s (larger and closer to Madrid), and the external one covers the rest, 22, of the suburban municipalities (smaller and more peripheral). It can be seen that the distribution of population and employment is very uneven ${ }^{12}$ (Fig. 3 and Table 6). The first ring contains more employment than population. The opposite occurs in the other rings, where there is more population than employment. Also, employment is more concentrated in northwest-northeast sector, while the population is more concentrated in the southsoutheast. Nevertheless, population distribution is more dispersed than employment.

The metropolitan area of Barcelona was divided into 60 zones and, in a way similar to Madrid, the metropolitan area was grouped into four different rings and six quadrants. The first ring includes 10 different spatial units; the second covers 11 outer areas of the municipality of Barcelona; the third ring includes 26 suburban municipalities; and the external one covers the rest of the suburban municipalities (13), smaller and more peripheral. It can be seen that the distribution of population and employment is very uneven (Fig. 4 and Table 7). The first ring contains more employment than population. The opposite occurs in the other rings, which have more population than employment. Also, employment is more concentrated near the area of the port of Barcelona, where an important industrial cluster is located, and the population is more concentrated near the coast of the Mediterranean Sea.

Access times by private car were calculated in ArcGIS, using a dense road network (Figs. 3 and 4). All metropolitan roads, as well the main streets of the cities of Madrid and Barcelona, were taken into account. The road networks represent the situation in 2010, and the average speed for each arc was estimated taking into account the type of road and the average level of congestion. With these networks, private car travel times to each terminal - Madrid-Atocha and Barcelona Sants HST Stations and Madrid Barajas and Barcelona El Prat Airports - were calculated for each of the centroids in both provinces.

Public transit times in Madrid were calculated using the Transport Information System from the Consorcio de Transportes in Madrid; those in Barcelona were calculating using the tool "Muévete con transporte público por Catalunya." Both route planners contain all public transit networks existing in 2010 (including urban and interurban bus, Metro and light and suburban rail). Thus, transit times to the terminals were calculated for each of the centroids of the areas under analysis. ${ }^{13}$

Population and employment data correspond to the year 2009. Population data were obtained from the Padrón and employment from the Directorio de Unidades de Actividad Económica. Both variables are provided by the Statistics Institute

\footnotetext{
12 After a suggestion made by a reviewer, the analysis was also complemented by quadrants that can be consulted in the Figs. 3 and 4 . Tables 6 and 7 also show the distribution of employment and population by quadrants and it can be seen that this is also quite uneven for both provinces, Madrid and Barcelona.

13 Both Transport Information Systems are based on GIS that are accessible by Internet in these websites: http://www.ctm-madrid.es/ and http://moute.gencat.cat/cercaltineraris.do?do=inici.
} 


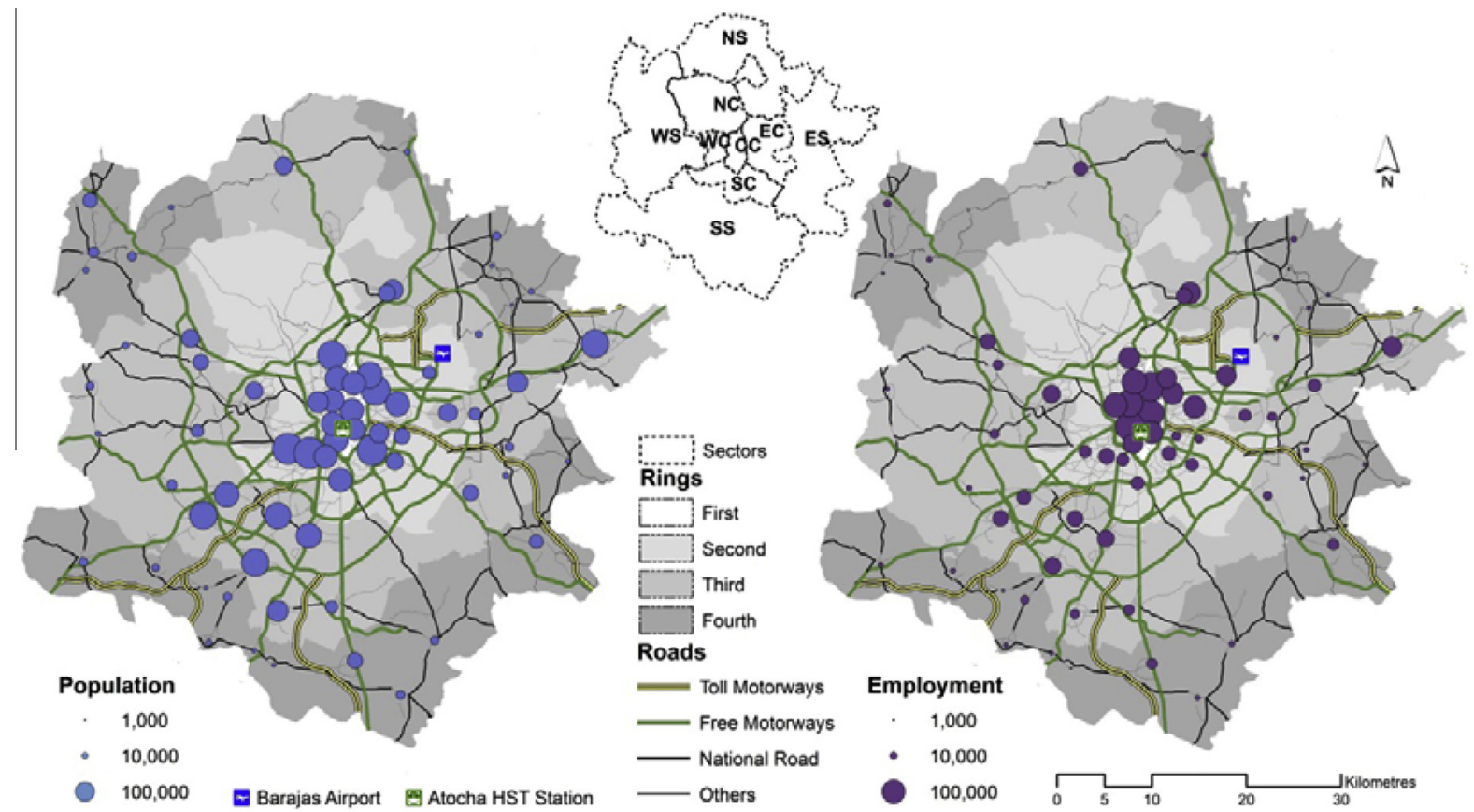

CC: City center; NC: Northern City; WC: Western City; SC: Southern City; EC Eastern City; NS: Northern Suburban; WS: Western Suburban; SS: Southern Suburban and ES: Eastern Suburban

Fig. 3. Population and employment distribution in the Madrid metropolitan area.

Table 6

Population and employment distribution in Madrid, according to rings and quadrants (2009).

\begin{tabular}{|c|c|c|c|c|c|c|c|}
\hline \multirow[t]{2}{*}{ Names } & \multirow[b]{2}{*}{ Spatial units } & \multicolumn{3}{|c|}{ Employment } & \multicolumn{3}{|l|}{ Population } \\
\hline & & Total & Mean & Std dev & Total & Mean & Std dev \\
\hline \multicolumn{8}{|l|}{ Rings } \\
\hline First & 7 & 886,966 & 126,709 & 35,213 & 821,795 & 117,399 & 53,275 \\
\hline Second & 14 & 753,559 & 53,826 & 31,716 & $2,158,811$ & 154,201 & 69,565 \\
\hline Third & 26 & 768,200 & 29,546 & 23,215 & $2,411,249$ & 92,740 & 71,047 \\
\hline Fourth & 22 & 133,912 & 6,087 & 6,148 & 551,385 & 25,063 & 31,808 \\
\hline Total & 69 & $2,542,637$ & 36,850 & 41,577 & $5,943,240$ & 86,134 & 74,978 \\
\hline \multicolumn{8}{|l|}{ Quadrants } \\
\hline City center (HST Station) & 7 & 886,966 & 126,709 & 35,213 & $1,014,004$ & 144,858 & 10,510 \\
\hline North City & 1 & 87,508 & 87,508 & & 224,849 & 224,849 & \\
\hline West City & 1 & 106,571 & 106,571 & & 118,114 & 118,114 & \\
\hline South City & 6 & 203,218 & 33,870 & 7,070 & $1,125,037$ & 187,506 & 74,636 \\
\hline East City (Airport) & 6 & 356,262 & 59,377 & 35,598 & 77,3940 & 128,990 & 68,824 \\
\hline North Suburban & 6 & 180,583 & 30,097 & 32,931 & 306,935 & 51,156 & 44,081 \\
\hline West Suburban & 13 & 174,422 & 13,417 & 18,149 & 472,620 & 36,355 & 28,184 \\
\hline South Suburban & 17 & 338,883 & 19,934 & 19,576 & $1,266,127$ & 74,478 & 78,830 \\
\hline East Suburban & 12 & 208,224 & 17,352 & 19,376 & 641,614 & 53,468 & 60,037 \\
\hline Total & 69 & $2,542,637$ & 36,850 & 41,577 & $5,943,240$ & 86,134 & 74,978 \\
\hline
\end{tabular}

Source: Statistics Institute of the Community of Madrid.

of the Community of Madrid and Catalunya, respectively. Population and employment data were used to calculate weighted indicators for access times and probability distribution.

Once, the GIS model has been explained regarding the areas of analysis and the networks for private car and public transit, we move forward to the next section where we will see how the spatial patterns around terminals are heterogeneous and so are the spatial competitiveness effects in the provinces of Madrid and Barcelona.

\subsection{Access time to terminals}

In this section the results of our network analysis regarding access times to terminals by public and private transport will be presented and discussed. In the analysis, the probability distribution for the spatial analysis for mandatory and non-man- 


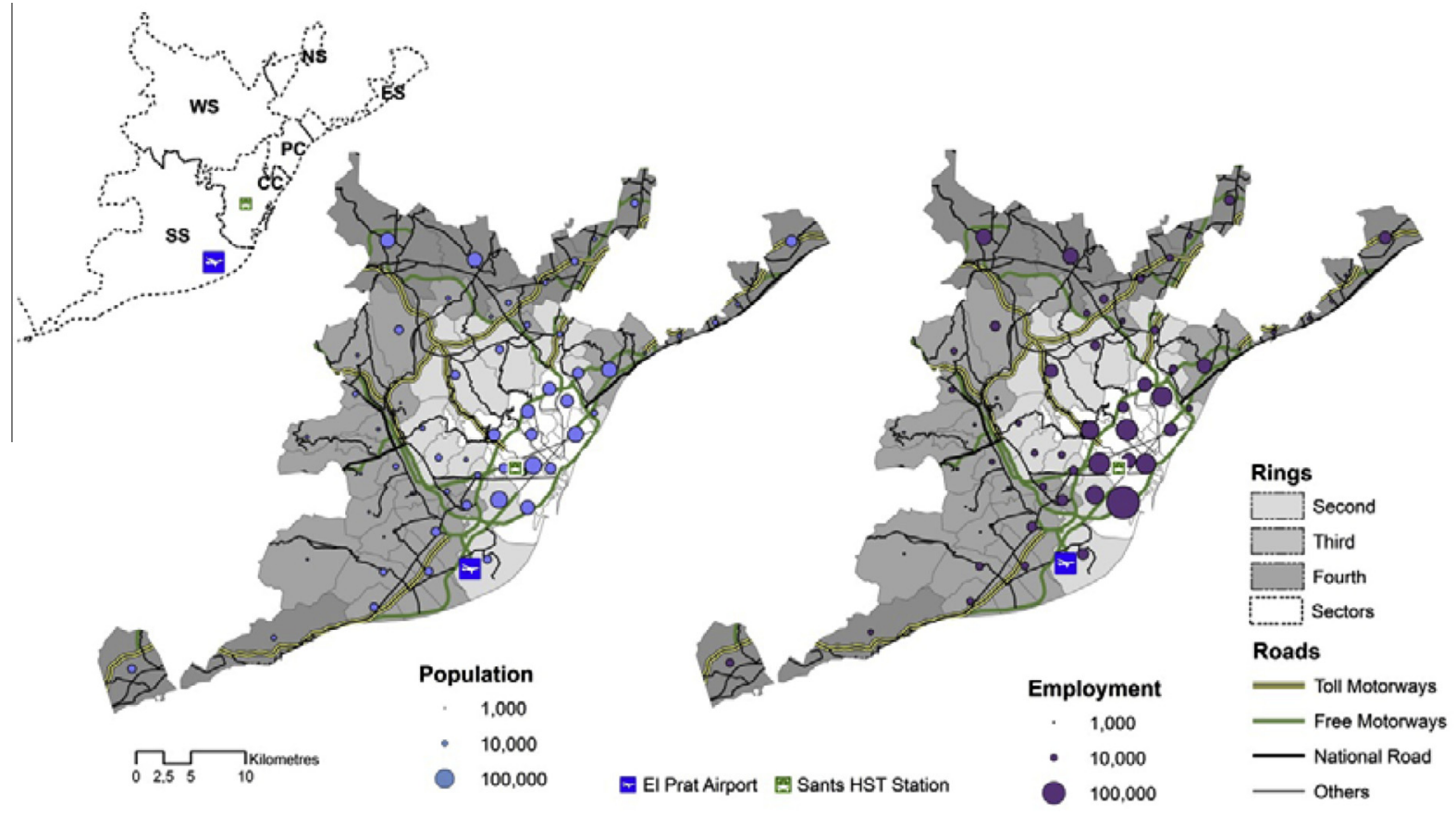

CC: City center; PC: Periphery City; NS: Northern Suburban; WS: Western Suburban; SS: Southern Suburban and ES: Eastern Suburban

Fig. 4. Population and employment distribution in the Barcelona metropolitan area.

Table 7

Population and employment distribution in Barcelona, according to rings and quadrants (2009).

\begin{tabular}{|c|c|c|c|c|c|c|c|}
\hline \multirow[t]{2}{*}{ Names } & \multirow[b]{2}{*}{ Spatial units } & \multicolumn{3}{|c|}{ Employment } & \multicolumn{3}{|l|}{ Population } \\
\hline & & Total & Mean & Std dev & Total & Mean & Std dev \\
\hline \multicolumn{8}{|l|}{ Rings } \\
\hline First & 10 & $1,621,537$ & 162153.7 & 55046.1 & $1,014,109$ & 101410.9 & 72585.7 \\
\hline Second & 11 & 775,046 & 70458.7 & 68317.1 & 295,001 & 26818.3 & 23842.5 \\
\hline Third & 26 & 912,937 & 35113.0 & 45596.5 & 287,039 & 11481.6 & 12992.6 \\
\hline Fourth & 13 & 862,113 & 66316.4 & 70062.6 & 283,209 & 21785.3 & 22718.6 \\
\hline Total & 60 & $4,171,633$ & 69527.2 & 71492.2 & $1,879,358$ & 31853.5 & 46182.2 \\
\hline \multicolumn{8}{|l|}{ Quadrants } \\
\hline City center (HST Station) & 10 & $1,014,109$ & 101,411 & 72,586 & $1,621,537$ & 162,154 & 55,046 \\
\hline Periphery City & 4 & 174,057 & 43,514 & 36,733 & 630,063 & 157,516 & 100,824 \\
\hline North Suburban & 3 & 49,492 & 16,497 & 10,219 & 130,774 & 43,591 & 22,850 \\
\hline West Suburban & 11 & 313,325 & 28,484 & 22,248 & 799,272 & 66,606 & 69,884 \\
\hline Sourth Suburban (Airport) & 24 & 265,385 & 11,058 & 9732 & 776,828 & 32,368 & 26,520 \\
\hline East Suburban & 7 & 62,990 & 8999 & 13,569 & 213,159 & 30,451 & 41,099 \\
\hline Total & 59 & $1,879,358$ & 31,854 & 46,182 & $4,171,633$ & 69,527 & 71,492 \\
\hline
\end{tabular}

Source: Statistics Institute of the Community of Catalunya.

datory trips will also be highlighted. As can be seen below, terminal accessibility has been calculated both with no weights and with weighting according to the distribution of population and employment for each of the centroids considered in our analysis. The competitiveness of transport modes is analyzed with respect to the spatial distribution of the odds of using air transport considering different scenarios; the analysis takes into account some other important values for the rest of the variables included in the modal competition model, such as prices, ${ }^{14}$ type of trip - mandatory versus leisure, and access mode to terminals - private versus transit. In order to facilitate somehow the interpretation of results, the maps of the odds distribution for each province, fixing some important zones which include the terminals for the other province, will be analyzed.

\footnotetext{
${ }^{14}$ Five different percentiles of price distribution for each of the modes were analyzed (10, 25, 50, 75 and 90). However, for ease of exposition, only the results of the analysis for the low price values will be presented.
} 
Access times to terminals by transport mode (minutes).

\begin{tabular}{|c|c|c|c|c|c|c|c|c|c|c|c|c|}
\hline & \multicolumn{4}{|c|}{ No weights } & \multicolumn{4}{|c|}{ Population weights } & \multicolumn{4}{|c|}{ Employment weights } \\
\hline & \multicolumn{2}{|c|}{$\begin{array}{l}\text { Madrid-Atocha HST } \\
\text { Station }\end{array}$} & \multicolumn{2}{|c|}{$\begin{array}{l}\text { Madrid-Barajas } \\
\text { Airport }\end{array}$} & \multicolumn{2}{|c|}{$\begin{array}{l}\text { Madrid-Atocha HST } \\
\text { Station }\end{array}$} & \multicolumn{2}{|c|}{$\begin{array}{l}\text { Madrid-Barajas } \\
\text { Airport }\end{array}$} & \multicolumn{2}{|c|}{$\begin{array}{l}\text { Madrid-Atocha HST } \\
\text { Station }\end{array}$} & \multicolumn{2}{|c|}{$\begin{array}{l}\text { Madrid-Barajas } \\
\text { Airport }\end{array}$} \\
\hline & Car & Transit & Car & Transit & Car & Transit & Car & Transit & Car & Transit & Car & Transit \\
\hline $\mathrm{N}$ & 69 & 69 & 69 & 69 & 69 & 69 & 69 & 69 & 69 & 69 & 69 & 69 \\
\hline Min & 3 & 11 & 7 & 7 & 3 & 11 & 7 & 7 & 3 & 11 & 7 & 7 \\
\hline Max & 46 & 86 & 56 & 98 & 46 & 86 & 56 & 98 & 46 & 86 & 56 & 98 \\
\hline Median & 25 & 38 & 29 & 59 & 21 & 27 & 26 & 55 & 17 & 26 & 21 & 39 \\
\hline Average & 24.7 & 43.3 & 29.2 & 55.6 & 20.7 & 32.3 & 26.8 & 50.7 & 17.6 & 31.3 & 23.7 & 42.6 \\
\hline Std dev & 10.0 & 21.0 & 10.7 & 21.1 & 9.7 & 15.3 & 8.5 & 16.8 & 9.4 & 14.6 & 7.8 & 17.5 \\
\hline \multirow[t]{3}{*}{$\mathrm{CV}$} & 40.3 & 48.5 & 36.5 & 38.0 & 46.8 & 47.4 & 31.6 & 33.1 & 53.7 & 46.6 & 33.1 & 41.1 \\
\hline & \multicolumn{2}{|c|}{$\begin{array}{l}\text { Barcelona-Sants HST } \\
\text { Station }\end{array}$} & \multicolumn{2}{|c|}{$\begin{array}{l}\text { Barcelona-El Prat } \\
\text { Airport }\end{array}$} & \multicolumn{2}{|c|}{$\begin{array}{l}\text { Barcelona-Sants HST } \\
\text { Station }\end{array}$} & \multicolumn{2}{|c|}{$\begin{array}{l}\text { Barcelona-El Prat } \\
\text { Airport }\end{array}$} & \multicolumn{2}{|c|}{$\begin{array}{l}\text { Barcelona-Sants HST } \\
\text { Station }\end{array}$} & \multicolumn{2}{|c|}{$\begin{array}{l}\text { Barcelona-El Prat } \\
\text { Airport }\end{array}$} \\
\hline & Car & Transit & Car & Transit & Car & Transit & Car & Transit & Car & Transit & Car & Transit \\
\hline $\mathrm{N}$ & 60 & 60 & 60 & 60 & 60 & 60 & 60 & 60 & 60 & 60 & 60 & 60 \\
\hline Min & 3 & 13 & 7 & 6 & 3 & 13 & 7 & 6 & 3 & 13 & 7 & 6 \\
\hline $\operatorname{Max}$ & 43 & 91 & 44 & 113 & 43 & 91 & 44 & 113 & 43 & 91 & 44 & 113 \\
\hline Median & 23 & 41 & 23 & 65 & 20 & 35 & 23 & 67 & 18 & 35 & 21 & 58 \\
\hline Average & 23.3 & 42.8 & 23.2 & 63.8 & 19.7 & 36.3 & 22.7 & 60.4 & 16.8 & 32.9 & 21.7 & 57.4 \\
\hline Std Dev & 8.9 & 14.4 & 8.7 & 18.7 & 10.0 & 13.2 & 8.3 & 18.1 & 10.4 & 13.7 & 7.8 & 18.0 \\
\hline $\mathrm{CV}$ & 38.1 & 33.6 & 37.4 & 29.3 & 50.8 & 36.4 & 36.6 & 29.9 & 62.0 & 41.7 & 35.6 & 31.4 \\
\hline
\end{tabular}

Source: Own elaboration.

It can be seen that the average access time to Madrid Barajas Airport by private car is $29.2 \mathrm{~min}, 18 \%$ higher than the access time to Madrid-Atocha HST Station, which is only $24.7 \mathrm{~min}$ (Table 8). The same analysis for public transport shows that access time to Madrid Barajas Airport is $55.6 \mathrm{~min}, 28 \%$ higher than access time to the train station (43.3 min). It is well known that Madrid Barajas Airport is one of the most important European airports, and that it occupies a central location inside the city of Madrid. However, it is clear that the train station performs better in terms of accessibility than the airport. This fact is not only explained in terms of location but also in terms of transport infrastructure. Madrid's public transport network is characterized by some central nodes, or hubs, one of which is Madrid-Atocha Station. As well as serving as the central station of the suburban railways network, it is also an important intermodal node for urban and interurban buses and the underground.

Table 8 also shows that average access time to Barcelona El Prat Airport by private car is quite similar (23.2 min) to the access time to Barcelona Sants HST Station (23.3). The same analysis for public transport shows that access time to Barcelona El Prat Airport is $63.8 \mathrm{~min}$, 49\% higher than the access time to the train station ( $42.8 \mathrm{~min}$ ). It can be seen that the train station performs much better than the airport in Barcelona in terms of terminal accessibility. This fact is again not only explained in terms of location but also of transport infrastructure. Barcelona Sants Station prevails as one of the central hubs in the public transport network of Barcelona. It is the central station of the suburban railways network and is also an important intermodal node for urban and interurban buses and the underground.

Weighted access times to terminals are also shown in Table 8. It can be seen that the concentration of employment and population in the inner rings explain the decrease in average accessibility times, leading to a better performance for the train station. The advantage of train stations in terms of accessibility is even more significant when the indicators are weighted by population. However, the relative positions of Madrid Barajas and Barcelona El Prat are highly influenced by the relative distribution of population and employment. In this case, access times to Madrid Barajas are negatively affected due to the highly concentrated urban areas from the south of Madrid, which are well connected with the train station and poorly connected with the airport. However, as employment is more concentrated in the northwest-northeast arc, this performance accessibility gap is reduced. Table 8 can also be used to emphasize how the accessibility to terminals in public transport is more dispersed than in private transport (see the coefficient of variation) for the case of Madrid, but that the opposite is true for the case of Barcelona. This reality will undoubtedly have an effect in the spatial modal competitiveness under analysis. It can also be seen that the accessibility to Madrid Atocha is more dispersed than accessibility to Madrid Barajas Airport, and again the opposite trend is observed in Barcelona, where the territorial cohesion around the airport is greater than around the station.

It is clear that access time to terminals is an important factor in the competitiveness of each transport mode, but is only a partial component inside the whole picture of competitiveness. It has been shown that other important variables are in-vehicle travel time, reliability, price, type of trip and comfort, among others. So, the issue that remains unanswered is whether this apparent better performance shown by train stations is diluted or reinforced at the spatial level of the province. For this 
reason, it will be necessary to analyze certain scenarios that accommodate different assumptions regarding price competition, type of trip and access mode. ${ }^{15}$

\subsection{Spatial analysis of modal competitiveness when price competition is fierce}

Besides the better performance shown by Madrid-Atocha Station regarding access times to terminals in public and private transport, it can be seen that for the first-scenario trip -that is, considering mandatory, private-car access and low-price trips as variables included in the modal competition model - the competitiveness of air transport is greater than the HST for both final destinations under analysis, even in the most favorable case when the final destination is in the zone that includes Barcelona Sants Station (Fig. 5) ${ }^{16}$. It can be seen that the odds of using air transport are always greater than 2. Another interesting conclusion that can be extracted from the figure is that there exists an important spatial effect in the competitiveness of HST versus air transport in the province of Madrid for both cases. It is clear that the zones in the southwest area of Madrid-Atocha Station show a better performance in terms of HST competitiveness than the rest of the areas of Madrid. It is also evident that when the trip has Barcelona El Prat as the final destination, the intensity of the better competitiveness of air transport is reinforced for all the zones of Madrid, where the odds are always greater than 3.4. ${ }^{17}$

Now a similar analysis will be presented having fixed the origin of the trips in the zones of Madrid that include MadridAtocha Station and Madrid Barajas Airport. In this case the spatial effects are observed in the province of Barcelona for mandatory and low-price trips. It can be observed that the competitiveness of air transport is greater than the HST for both origins under analysis, even in the most favorable case, in which the origin is the zone that includes Madrid-Atocha Station (Fig. 6). It can be seen that the odds of using air transport are always at least 2.39. Another interesting conclusion that can be extracted from the figure is that again there exists an important spatial effect in the competitiveness of the HST versus air transport in Barcelona, and air transport is not as competitive as in the reciprocal case analyzed previously. It is clear that space competition is important and that access time in the province of Barcelona tends to favor the competitiveness of the HST. ${ }^{18}$ Again there is a clear line between the areas near Barcelona Sants Station, which favor the competitiveness of the HST, and the hinterland of the airport, which favors the competitiveness of air transport.

Now the focus will be turned to another interesting scenario, in which low-price tickets are still considered, but other important variables in the modal competition model are changed to transit access and leisure trips. In this case, it can be seen that the competitiveness of air transport is greater than that of the HST for both final destinations under analysis and most of the areas of Madrid. However, in this scenario when the most favorable case is analyzed - the destination is in the zone that includes Barcelona Sants Station - Fig. 7 shows that the HST is more competitive for the zone that includes Madrid-Atocha Station and for the majority of the areas to the south of Madrid-Atocha Station. It is again relevant that there is an important spatial effect in the competitiveness of the HST versus air transport in the province of Madrid for both cases and when the destination is in the area than includes Barcelona El Prat Airport, it can be seen that the odds of using air transport are always at least 2.93, but again the odds of using air transport are always lower than in the first scenario. For this reason it can be concluded that public transport access for leisure trips tends to favor HST competitiveness in a scenario with low-price tickets.

Fig. 8 presents the reciprocal analysis, fixing the origin of the trips in the zones of Madrid that includes Madrid-Atocha Station and Madrid Barajas Airport and analyzing the spatial competition in the province of Barcelona for leisure, transitaccess and low-price trips. It can be observed that the HST is now competitive when the origin of the trip is made in the area that includes Madrid-Atocha. In this case, the HST is clearly more competitive than air transport in the area of Barcelona Sants Station and in most of the areas of the north of the Barcelona Sants Station. This result reinforces the comment of SDG, 2006:

Although incumbent operators did not appear to think actively about the location or accessibility of terminals, as it generally cannot be changed in the medium term, this was a key factor determining market share. For example, the good location of the airports on the Madrid-Barcelona route contributed to high air market share; in contrast, the relatively poor location of the airports on the Paris-Marseille route contributed to high rail market share. (p. 8)

It is still interesting to note the evidence of an important spatial effect in the competitiveness of the HST versus air transport in Barcelona, and air transport is not as competitive as in the reciprocal case analyzed previously. It is clear that space

\footnotetext{
$\overline{15}$ It can be seen that for five different price assumptions for each transport mode, two types of trips and two access modes, a total of 100 different scenarios are obtained. Having in mind that there are 4140 different origin and destination zones, the challenge here is to present some sensible information from 414000 cells of relevant information which shows that the access time to terminals plays an important role in explaining the spatial competitiveness of HST versus air transport in the corridor.

${ }^{16}$ All the figures of the GIS analysis are based on parameter point estimates obtained from the choice model. Authors are aware that the interpretation of results could vary with the accuracy of parameter estimates. However, note that as principal parameters were estimated with a high level of significance, then the level of accuracy of the GIS analysis is expected to be adequate. The computation of confidence intervals for the odds ratios is out of the scope of this paper and is left for future research.

17 This analysis was suggested by Professor Aura Reggiani, when a draft of this paper was presented at the Annual Nectar Conference held in Antwerp in 2011. In this case, it is clear that air transport is more price competitive than HST. During its fall advertising campaign, Renfe - the HST operator in Spain - has announced a more aggressive offer in price discounts for all the routes of AVE with a web price yielding discounts of up to $60 \%$.

${ }^{18}$ It is important to remember that the individual's perception of the transport modes competitiveness is affected by the intensity of the disutility associated with the access time depending on the OD pair considered in the analysis.
} 

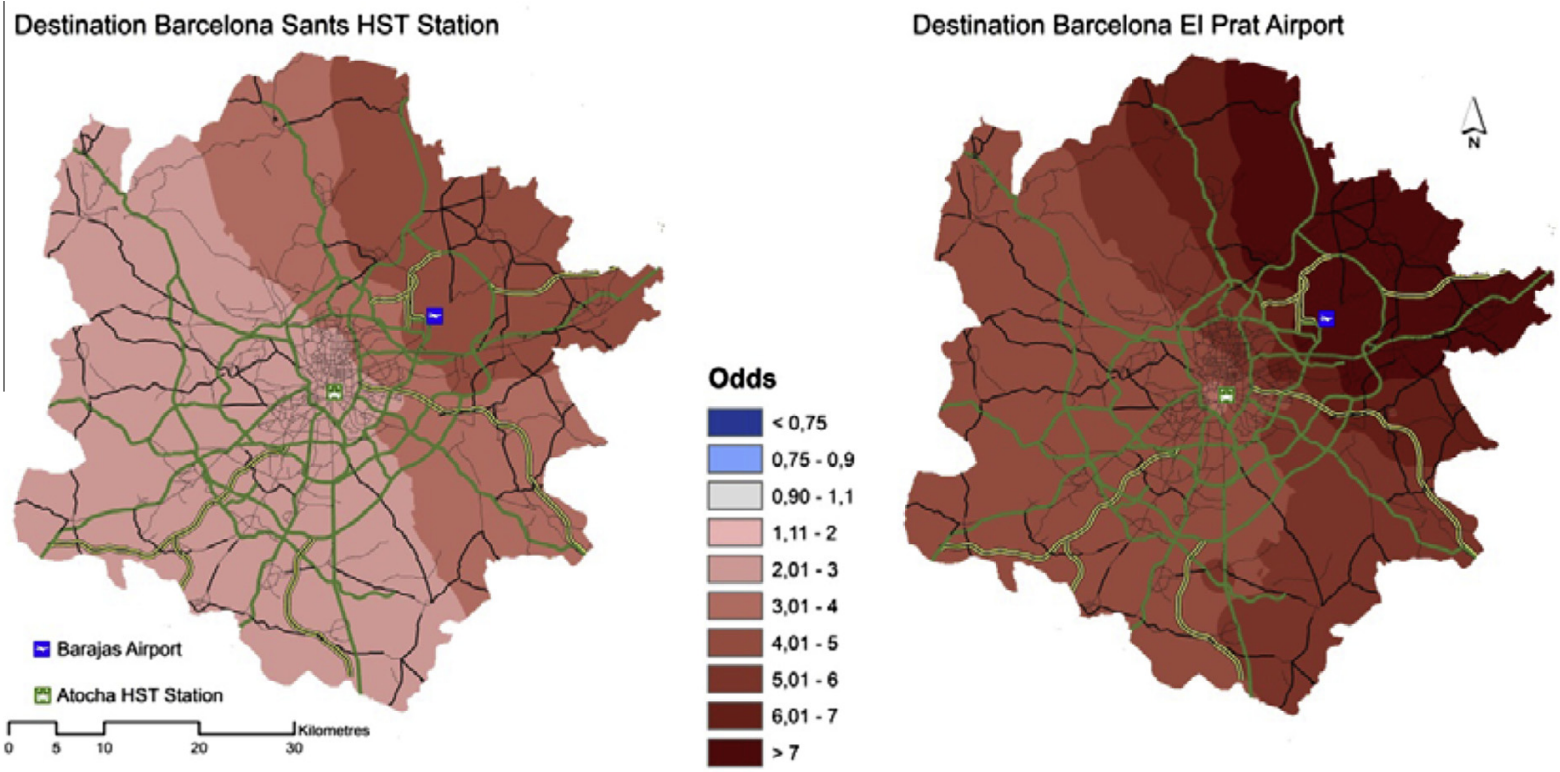

Fig. 5. Spatial distribution of the odds of using air transport in the province of Madrid for mandatory, private-car-access, low-price trips.

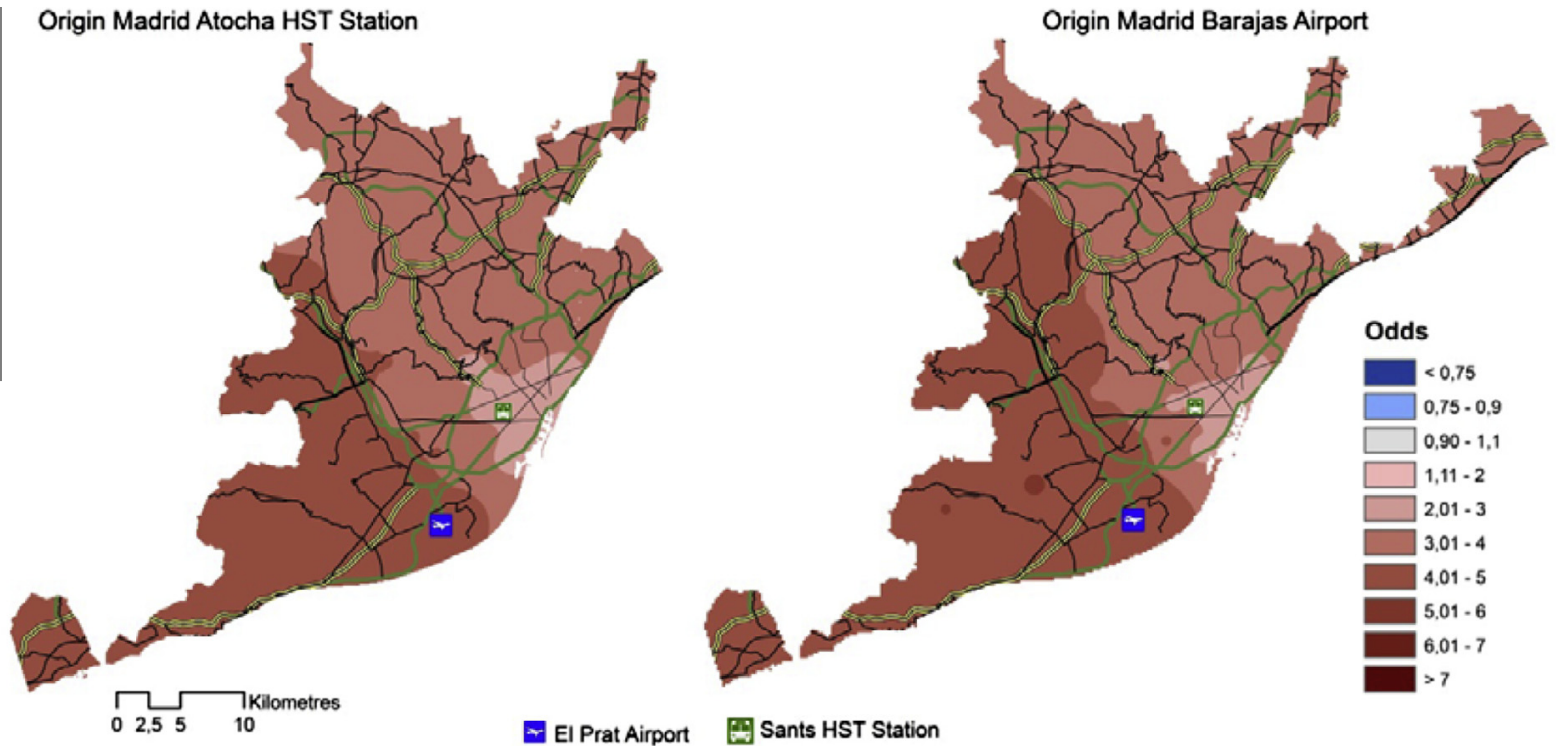

Fig. 6. Spatial distribution of the odds of using air transport in the province of Barcelona for mandatory, private-car-access, low-price trips.

competition is important and that access time in the province of Barcelona tends to favor the competitiveness of the HST. Again there is a clear line between the areas near Barcelona Sants Station, which favor the competitiveness of the HST, and the hinterland of the airport, which favors the competitiveness of air transport. However, in this scenario, even when the origin is Madrid Barajas Airport, the less favorable case, ceteris paribus, for the HST, it can still be seen that for the area including Barcelona Sants Station, the HST is more competitive than air transport.

To summarise, it has been shown that access to terminals plays an important role determining the competitiveness of both transport modes. Access by private car tends to favor the relative competitiveness of air transport. On the other hand, public transport access tends to decrease the competitive advantage of air transport, and in the case of leisure trips it can be seen that in some cases the HST is even more competitive when the origin is Madrid-Atocha and the destination is in the hinterland area of Barcelona Sants Station. 

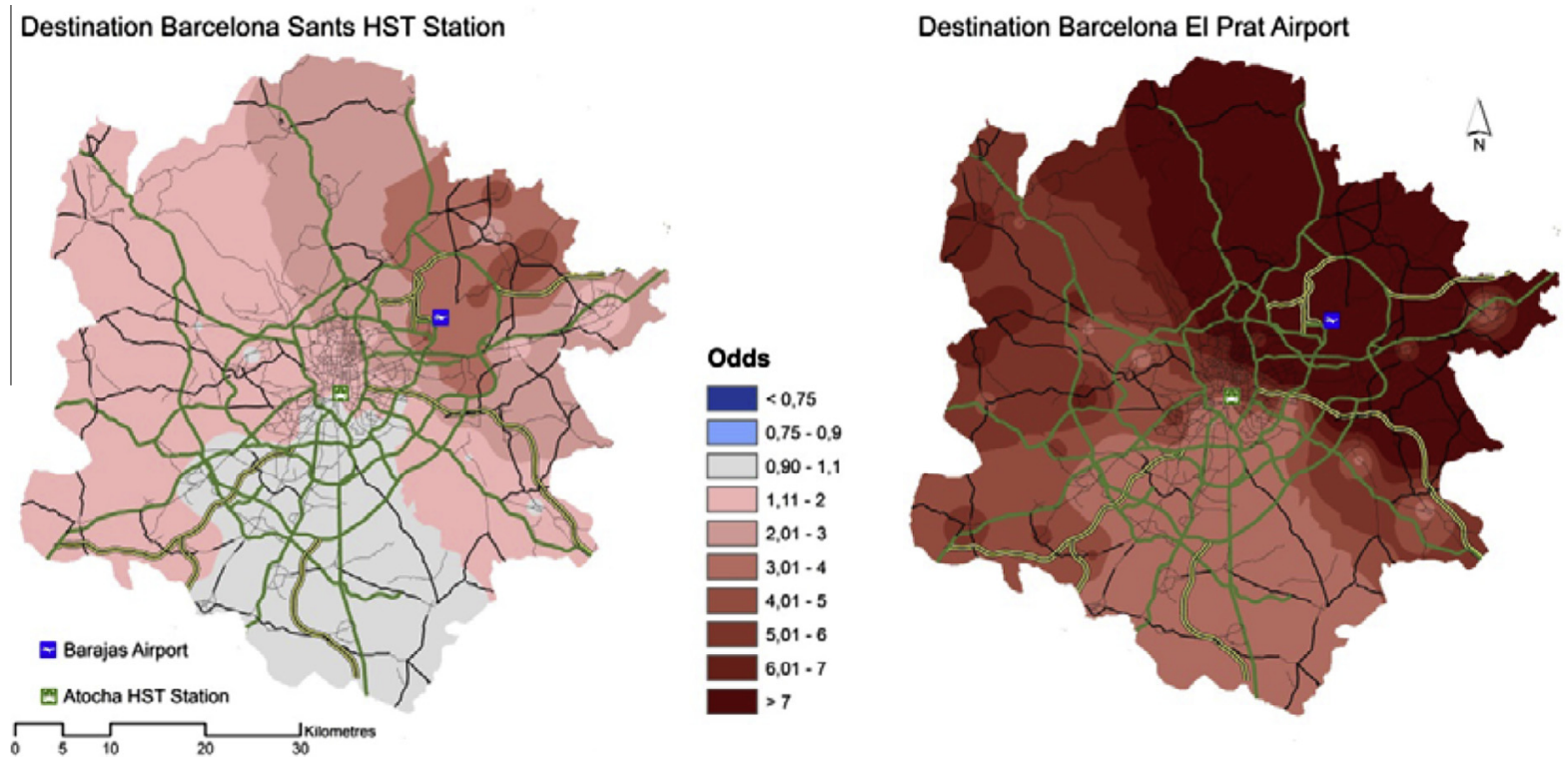

Fig. 7. Spatial distribution of the odds of using air transport in the province of Madrid for leisure, transit-access, low-price trips.

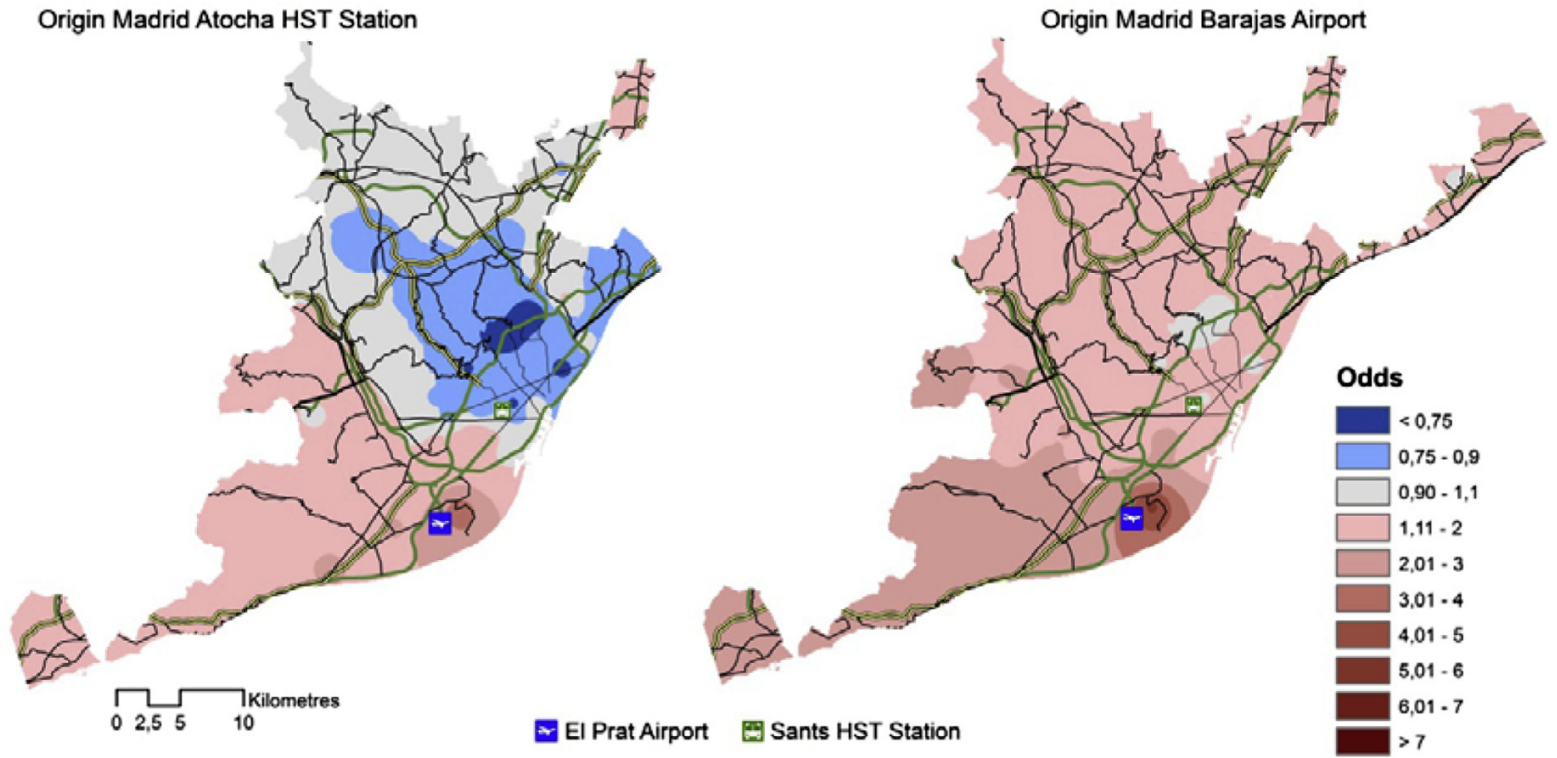

Fig. 8. Spatial distribution of the odds of using air transport in the province of Barcelona for leisure, transit-access, low-price trips.

\section{Conclusions}

This paper sheds some light on an often neglected factor that affects passengers' behavior in interurban corridors - access time to terminals, train stations and airports - in order to analyze the relative spatial competitiveness of air versus HST transport in the metropolitan areas of Madrid and Barcelona for a particular corridor in Spain: Madrid-Barcelona.

It has been shown that the time involved in accessing terminals is a key factor in determining spatial competitiveness of transport modes and that this competitiveness depends on different characteristics, such as whether the trip is mandatory or not, the chosen access mode and the price of the tickets. In this paper, special attention has been paid to the case where price competition is fierce, that is, for the market segment of low-price tickets. In general, it is usually assumed that rail stations present better accessibility than airports because rail stations tend to be in the central business districts. 
Our spatial analysis has shown that private transport tends to support the relative competitiveness of air transport in the corridor and that, on the other hand, public transport decreases this better position of air transport. It is also clear that in some zones the existence of suburban railways networks favors the competitiveness of the HST.

Therefore, the relative accessibility levels to terminals play an important role that should not be neglected in order to determine the overall competitiveness of different travel modes in interurban corridors. Thus, a policy that incorporated high penalties for private transport in the surrounding areas of airports would increase the relative competitiveness of the HST.

It has been found that the location of terminals is strategic in terms of two different related issues: relative location (given users' spatial origin/destination) and connections with fast public transport networks (underground and regional trains). Nowadays, many cities are evolving as metropolitan areas with large and low-density suburbs. As a result, many citizens live and/or work away from the city center. This could likely influence the terminal location issue as well as access to these terminals by different transport modes, especially private and public transport. In both cities, Madrid and Barcelona, HST stations are centrally located and show better accessibility by car and particularly by public transport than airports, located on the periphery. From the point of view of the planning process, the results verify that the decision to locate HST stations in the inner city influences clearly access and egress times and, this is critical in order to increase the potential attractiveness of HSTs improving the ridership.

Finally, our paper shows that the conjoint use of two well-known tools, such as discrete choice demand analysis and GIS, makes a significant contribution to analyzing the relative spatial competitiveness of transport modes in scenarios such as the one analyzed here: interurban transport corridors.

We wish to thank three anonymous reviewers for their useful comments and suggestions. We acknowledge support under the program of research and development of the Spanish Ministry of Science and Innovation (Projects TRA200806682 and PT-2007-027-01CAPM).

Albalate, D., Bel, G., 2012. The Economics and Politics of High-Speed Rail. Lexinton Books, Plymouth.

Bel, G., 1997. Changes in travel time across modes and its impact on the demand for inter-urban rail travel. Transp. Res. Part E: Logistics Transp. Rev. 33 (1), 43-52.

Ben-Akiva M. E., Morikawa T. 1990. Estimation of travel demand models from multiple data sources. In: Proceedings of the 11th International Symposium on Transportation and Traffic Theory, Yokohama.

Bliemer, M.C.J., Rose, J.M., 2011. Experimental design influences on stated choice outputs: an empirical study in air travel choice. Transp. Res. A 45 (1), $63-$ 79.

Bradley, M.A., Daly, A.J., 1997. Estimation of logit choice models using mixed stated preference and revealed preference information. In: Stopher, P.R., LeeGosselin, M. (Eds.), Understanding Travel Behavior in an Era of Change. Pergamon, Oxford, pp. 209-232.

Chang, I., Chang, G.-L., 2004. A network-based model for estimating the market share of a new high speed rail system. Transp. Planning Technol. 27 (2), 6790.

Chang, J.S., Lee, J., 2008. Accessibility analysis of korean high-speed rail: a case study of the seoul metropolitan area. Transp. Rev. 28 (1), 87-103.

Cherchi, E., de D. Ortúzar, J., 2004. On fitting mode-specific constants in the presence of new options in RP/SP models. Transp. Res. A 40, 1-18.

Chou, J.-S., Kim, C., Kuo, Y.-C., Ou, N.-C., 2011. Deploying effective service strategy in the operations stage of high-speed rail. Transp. Res. Part E: Logistics Transp. Rev. 47 (4), 507-519.

Clever, R., Hansen, M.M., 2008. Interaction of air and high-speed rail in japan. Transp. Res. Record: J. Transp. Res. Board 2043 (1), 1-12.

Dobruszkes, F., 2011. High-speed rail and air transport competition in Western Europe: a supply-oriented perspective. Transp. Policy 18, 870-879.

Domencich, T.A., McFadden, D., 1975. Urban Travel Demand: A Behavioural Analysis. North Holland, Amsterdam.

Fröidh, O., 2005. Market effects of regional high-speed trains on the Svealand line. J. Transp. Geography 13 (4), 352-361.

Givoni, M., Dobruszkes, F., 2013. A review of ex-post evidence for mode substitution and induced demand following the introduction of high-speed rail. Transp. Rev. 33 (6), 720-742.

Givoni, M., Rietveld, P., 2007. The access journey to the railway station and its role in passengers' satisfaction with rail travel. Transp. Policy 14 (5), 357-365.

Gonzalez-Savignat, M., 2000. Preferencias declaradas con diseño de experimentos: Una aplicación al tren de alta velocidad. Universidad de Vigo, Tesis Doctoral.

González-Savignat, M., 2004. Competition in air transport, the case of high speed train. J. Transp. Econ. Policy 38 (1), 77-108.

Gutiérrez, J., 2001. Location, economic potential and daily accessibility: an analysis of the accessibility impact of the high-speed line. J. Transp. Geography 9 (4), 229-242.

Gutiérrez, J., González, R., Gómez, G., 1996. The European high-speed train network: predicted effects on accessibility patterns. J. Transp. Geography 4 (4), $227-238$.

Huang, J., Morgan, C. 2011. Case Studies Examining High Speed Rail Station Location Decisions From an International Perspective. 2011 Joint Rail Conference (ed.) American Society of Mechanical Engineers, 517-526.

Ioannidis, C., Peel, D.A., 2005. Testing for market efficiency in gambling markets when errors are non-normal and heteroskedastic: an application of the wild bootstrap. Econ. Lett. 87 (2), 221-226.

Ivaldi, M., Vibes, C. (2005. Intermodal and intramodal competition in passenger rail transport. CEPR Discussion Paper no. 5004

Jara-Díaz, S.R., 1998. Time and income in travel choice: towards a microeconomic activity-based theoretical framework. In: Garling, T., Laitila, T., Westin, K. (Eds.), Theoretical Foundations of Travel Choice Modeling. Elsevier Science, New York, pp. 51-74.

Jara-Díaz, S.R., Farah, M., 1987. Transport demand and users' benefits with fixed income: the goods/leisure trade-off revisited. Transp. Res. B 21, 165-170. Louviere, J.J., Hensher, D.A., Swait, J.D., 2000. Stated Choice Methods: Analysis and Application. Cambridge University Press, Cambridge.

Mao, J., 2010. Air vs rail competition towards the Beijing-Shanghai high-speed railway project in China. J. Air Transp. Stud. 1 (2), $42-58$.

Martens, K., 2004. The bicycle as a feedering mode: experiences from three European countries. Transp. Res. Part D 9, 281-294.

Martín, J.C., Nombela, G., 2007. Microeconomic impacts of investments in high speed trains in Spain. Ann. Regional Sci. 41 (3), 715-733.

Martín, J.C., Gutiérrez, J., Román, C., 2004. Data envelopment analysis (DEA) index to measure the accessibility impacts of new infrastructure investments: the case of the high-speed train corridor Madrid-Barcelona-French border. Regional Stud. 38 (6), 697-712. 
McFadden, D., 1981. Econometric models of probabilistic choice. In: Manski, C., Mcfadden, D. (Eds.), Structural Analysis of Discrete Choice Data with Econometric Applications. MIT Press, Cambridge, MA, pp. 198-272.

de D. Ortúzar, J., Willumsen, L.G., 2001. Modelling Transport, 3rd ed. John Wiley \& Sons, Chichester.

Pagliara, F., Vassallo, J.M., Roman, C., 2012. High-speed rail versus air transportation. case study of Madrid-Barcelona, Spain. Transp. Res. Record: J. Transp. Res. Board 2289, 10-17.

Pels, E., Nijkamp, P., Rietveld, P., 2000. Airport and airline competition for passengers departing from a large metropolitan area. J. Urban Econ. 48, 29-45.

Pels, E., Nijkamp, P., Rietveld, P., 2001. Airport and airline choice in a multiple airport region: an empirical analysis for the San Francisco bay area. Regional Stud. 35 (1), 1-9.

Pels, E., Nijkamp, P., Rietveld, P., 2003. Access to and competition between airports: a case study for the San Francisco bay area. Transp. Res. 37A (1), 71-83. Rietveld, P., 2000. The accessibility of railway stations: the role of the bicycle in The Netherlands. Transp. Res. Part D 5, $71-75$.

Román, C., Martín, J.C., 2011. The effect of access time on modal competition for interurban trips: the case of the Madrid-Barcelona corridor in Spain. Networks Spatial Econ. 11 (4), 661-675.

Román, C., Espino, R., Martín, J.C., 2007. Competition of high-speed train with air transport: the case of Madrid-Barcelona. J. Air Transp. Manage. 13 (5), 277 284.

Román, C., Espino, R., Martín, J.C., 2010. Analyzing competition between the high speed train and alternative modes. the case of the Madrid-ZaragozaBarcelona corridor. J. Choice Modell. 3 (1), 84-108.

Schönharting, J., Schmid, A., Franka, A., Bremer, S., 2003. Towards the multimodal transport of people and freight: interconnective networks in the RheinRuhr Metropolis. J. Transp. Geography 11, 193-203.

Steer Davies Gleave - SDG. 2006. Air and rail competition and complementarity. Final Report. Prepared for European Commission DG TREN.

Tapiador, F., Burckhart, K., Martihenneberg, J., 2009. Characterizing European high speed train stations using intermodal time and entropy metrics. Transp. Res. Part A 43 (2), 197-208.

Vickerman, R.W., Spiekermann, K., Wegener, M., 1999. Accessibility and economic development in Europe. Regional Stud. 33 (1), 1-15.

Wardman, M., Tyler, J., 2000. Rail network accessibility and the demand for inter-urban rail travel. Transp. Rev. 20 (1), 3-24.

Williams, H.C.W.L., 1977. On the formation of travel demand models and economic evaluation measures of user benefit. Environ. Planning 9A, 285-344. 